\title{
Macro-microangiopathy and endothelial dysfunction in NIDDM patients with and without diabetic nephropathy
}

\author{
H .-H . Parving ${ }^{1}$, F. S. N ielsen ${ }^{1}$, L . E . B ang ${ }^{1}$, U . M. Smidt ${ }^{1}$, T. L. Svendsen ${ }^{2}$, J .-W. Chen ${ }^{1}$, M .-A . G all ${ }^{1}$, P. R ossing ${ }^{1}$ \\ ${ }^{1}$ Steno D iabetes Center, G entofte, D enmark \\ ${ }^{2}$ D epartment of I nternal M edicine, County Central H ospital, N æstved, D enmark
}

Summary The Steno hypothesis suggests that albuminuria reflects widespread vascular damage (proliferative retinopathy and severe macroangiopathy) due to a generalized vascular (endothelial) dysfunction. We assessed this concept in NID D M (non-insulin-dependent diabetic) patients with (13 female/ 39 male, age $60 \pm 7$ years, group 1) and without ( $12 \mathrm{fe}-$ male/41 male, age $61 \pm 7$ years, group 2) diabetic nephropathy compared to matched non-diabetic subjects ( 7 female/15 male, age $58 \pm 8$ years, group 3 ). A 12-lead ECG was recorded and coded blindly using the $M$ innesota $\mathrm{R}$ ating Scale; the World $\mathrm{H}$ ealth $\mathrm{O}$ rganization cardiovascular questionnaire was used to assess past and present evidence of myocardial infarction, angina pectoris, stroke, and peripheral vascular disease (digital systolic blood pressure determination). The degree of diabetic retinopathy was scored from fundus photography. The following variables were measured: transcapillary escape rate of albumin (initial disappearance of intravenously injected ${ }^{125}$ labelled human serum albumin), plasma concentrations of prorenin (radioimmunoassay) and serum concentrations of von Willebrand factor (enzymelinked immunoadsorbent assay). Prevalence of ischaemic heart disease (ECG reading) (49/20/5)\% and peripheral vascular disease as indicated by reduced systolic blood pressure on big toe (69/30/
14)\% was significantly higher in group 1 vs group 2 $(p<0.01)$ and in group 2 vs group $3(p<0.01)$, respectively. The prevalence and severity of retinopathy was higher in group 1 vs $2(p<0.01)$. Transcapillary escape rate of albumin $(\% / h)$ was elevated in group 1 and 2 as compared to control subjects: 7.9 (4.3-13.7); 7.4 (3.7-16.4) vs $6.0(3.4-8.7),(p<0.005)$, respectively. Plasma prorenin activity $(\mathrm{IU} / \mathrm{ml})$ was raised in group 1 and group 2 as compared to group 3: 272 (59-2405); 192 (18-813), and 85 (28-246), $p<0.001$, respectively. Serum von Willebrand factor (IU/ $\mathrm{ml}$ ) was elevated in group 1 as compared to group 2 and 3: $2.07(0.83-4.34) ; 1.60(0.30-2.99)$ and 1.50 $(1.00-2.38), p<0.001$, respectively. 0 ur study demonstrated that NIDDM patients with and without albuminuria had increased transcapillary escape of albumin and raised prorenin activity, whereas only those with albuminuria had increased von Willebrand factor. Patients with NIDDM may have abnormal endothelial function in the absence of albuminuria. [D iabetologia (1996) 39: 1590-1597]

Keywords Non-insulin-dependent diabetes mellitus, diabetic microangiopathy, diabetic nephropathy, capillary permeability, endothelium, haemodynamics, cardiovascular disease.
Corresponding author: Dr. H.-H. Parving, Steno Diabetes Center, N iels Steensens vej 2, D k-2820 G entofte, D enmark A bbreviations: B P, arterial blood pressure; TE $\mathrm{R}_{\text {alb, }}$, transcapillary escape rate of albumin; IV $M_{\text {alb }}$, intravascular mass of albumin; vWF, von Willebrand factor; IDDM, insulin-dependent diabetes mellitus; NIDDM, non-insulin-dependent diabetes mellitus.
Insulin-dependent diabetic (ID D M ) patients with incipient and overt diabetic nephropathy are characterized by a higher incidence and prevalence of retinopathy and cardiovascular diseases than normoalbuminuric ID D M patients [1, 2]. The relative cardiovascular mortality is approximately 40 times higher in diabetic nephropathy as compared to the age-matched population [1]. Furthermore, the prevalence of 
Table 1. Clinical data in NID D M patients with normoal buminuria or diabetic nephropathy and control subjects

\begin{tabular}{|c|c|c|c|c|}
\hline & Control subjects & $\begin{array}{l}\text { NIDDM patients with } \\
\text { normoalbuminuria }\end{array}$ & $\begin{array}{l}\text { NID D M patients } \\
\text { with nephropathy }\end{array}$ & $\overline{p \text {-value }}$ \\
\hline Sex (male/female) & $15 / 7$ & $41 / 12$ & $39 / 13$ & NS \\
\hline A ge (years) & $58 \pm 8$ & $61 \pm 7$ & $60 \pm 7$ & NS \\
\hline Treatment (\% ) (diet/oral hypoglycaemic agent/insulin) & & $26 / 51 / 23$ & $8 / 44 / 48$ & b \\
\hline $\mathrm{HbA}_{1 \mathrm{c}}(\%)$ & $5.7 \pm 0.4$ & $8.1 \pm 1.4$ & $8.7 \pm 1.9$ & $d, e, c$ \\
\hline B lood glucose $(\mathrm{mmol} / \mathrm{l})$ & $4.7 \pm 0.5$ & $10.1 \pm 3.0$ & $11.8 \pm 4.2$ & $d, e, c$ \\
\hline a U rinary albumin excretion rate (mg/24 h) & $6(2-29)$ & $9(2-29)$ & $1181(270-9972)$ & \\
\hline a Serum creatinine $(\mu \mathrm{mol} / \mathrm{l})$ & $87(61-122)$ & $79(45-119)$ & $96(57-306)$ & $b, f$ \\
\hline G lomerular filtration rate $\left(\mathrm{ml} \cdot \mathrm{min}^{-1} \cdot 1.73 \mathrm{~m}^{-2}\right)$ & & $97 \pm 17$ & $71 \pm 31$ & b \\
\hline Systolic blood pressure ( $\mathrm{mm} \mathrm{H} \mathrm{g)}$ & $137 \pm 25$ & $143 \pm 19$ & $166 \pm 23$ & $b, e$ \\
\hline Diastolic blood pressure $(\mathrm{mm} \mathrm{H}$ g) & $82 \pm 11$ & $82 \pm 9$ & $89 \pm 12$ & $b, f$ \\
\hline
\end{tabular}

Mean \pm SD indicated, except, ${ }^{a}$ median (range); ${ }^{b} p<0.001$ comparing NIDDM patients with normoalbuminuria vs nephropathy; ${ }^{c} p<0.05$ comparing NIDDM patients with normoalbuminuria vs nephropathy; ${ }^{d} p<0.001$ comparing control

proliferative retinopathy and blindness is five to seven times higher in IDDM patients with than without diabetic nephropathy [2].

Several studies in ID D M patients with abnormally elevated urinary albumin excretion rate have demonstrated raised values of: transcapillary escape of albumin (TE R ${ }_{a l b}$ ) [3-6]; plasma von Willebrand factor ( VW F ) [7, 8]; plasma prorenin activity [9-12]; and angiotensin-converting enzyme activity [13]. R educed release of tissue plasminogen activator has also been demonstrated in the above mentioned patients [14]. These findings led D eckert et al. [15] to advocate the Steno concept suggesting that albuminuria reflects widespread vascular damage (proliferative retinopathy and severe macroangiopathy) due to a generalized vascular (endothelial) dysfunction. R ecently, we have shown a progressive rise in serum concentration of VW $F$ with increasing urinary albumin excretion in NIDDM patients [16].

The aim of our cross-sectional study was to further evaluate the validity of the Steno hypothesis in NID DM patients with diabetic nephropathy by simultaneous determination of $T E R_{a l b}$, plasma prorenin activity and serum concentration of VW F.

\section{Subjects and methods}

A II 65 albuminuric NID D M patients with diabetic nephropathy, attending the outpatient clinic at $\mathrm{H}$ vidöre $\mathrm{H}$ ospital were identified from our patient register as previously described [17]. D iabetic nephropathy was diagnosed clinically $(n=45)$ if the following criteria were fulfilled: persistent albuminuria above $300 \mathrm{mg} / 24 \mathrm{~h}$, presence of diabetic retinopathy and no clinical or laboratory evidence of other kidney or renal tract disease, other than diabetic glomerulosclerosis [18]. A the onset of persistent albuminuria 20 of the above-mentioned $65 \mathrm{pa}$ tients lacked retinopathy and thus did not meet the clinical criteria for diabetic nephropathy. A kidney biopsy was performed in all these 20 patients revealing diffuse or nodular diabetic subjects vS NIDDM patients with normoalbuminuria; e $p<0.001$ comparing control subjects vs NIDDM patients with nephropathy; ${ }^{f} p<0.05$ comparing control subjects with NIDDM patients with nephropathy glomerulosclerosis. The patients were considered to have NIDDM if they were treated with diet alone, or in combination with oral hypoglycaemic agents, or if they were treated with insulin and had an onset of diabetes after the age of 40 years and a body mass index (BMI) above normal ( $\geq 25$ $\mathrm{kg} / \mathrm{m}^{2}$ in females, $\geq 27 \mathrm{~kg} / \mathrm{m}^{2}$ in males) at the time of diagnosis [19]. A II insulin-treated patients had a glucagon test performed, and NIDD M was diagnosed if a stimulated C-peptide value was $0.60 \mathrm{pmol} / \mathrm{ml}$ or more [20]. The glucagon/C-peptide test was carried out after an overnight fast. Blood samples for plasma C-peptide determination were obtained before and $6 \mathrm{~min}$ after an i.v. bolus injection of $1 \mathrm{mg}$ glucagon ( $\mathrm{N}$ ovo N ordisk, B agsværd, D enmark) as described previously [20]. N ine NIDDM patients with diabetic nephropathy did not participate in the present study: seven patients did not want to participate, one patient had prostatic cancer, and one died before the start of study. Thus 56 NID D M patients suffering from diabetic nephropathy were included in the study. Fifty-six NIDDM patients with normoalbuminuria (urinary albumin excretion rate $<30 \mathrm{mg} / 24 \mathrm{~h}$ ) matched for sex, age, and known duration of diabetes served as a control group. Furthermore, 25 non-diabetic subjects matched for sex, age, BMI and arterial blood pressure (BP) as compared to the normoalbuminuric diabetic group served as a non-diabetic control group. These patients were recruited from a population study where the patients were randomly selected from the local community register in an age and gender stratified fashion. Individuals with a history of hypertension, diabetes, kidney disease, illness in the previous 2 weeks, pregnancy or were performing night-duty were excluded. Subjects with incidently discovered hypertension were included in the study. A fter examination three of these non-diabetic subjects were excluded due to the following reasons: diabetes $(n=2)$ and albuminuria $(n=1)$. Thus 22 non-diabetic subjects were included. D ue to failure in obtaining valid measurements of TER alb (see below) the final number of patients studied successfully were 52 NIDDM patients with nephropathy, 53 NIDD M patients with normoalbuminuria and 22 nondiabetic subjects (Table 1 and 2 ). We have previously reported the serum concentration of VWF in 10 and 36 of the NIDDM patients with and without diabetic nephropathy, respectively [16]. The interval between the two measurements was 56 years. All subjects included in the study were Caucasians, and all gave their informed consent to participate in the study. The study was approved by the regional ethics committee. 
Table 2. Prevalence of antihypertensive treatment, cardiovascular disease and smoking in NID D M patients with normoalbuminuria or diabetic nephropathy and control subjects

\begin{tabular}{|c|c|c|c|c|}
\hline & Control subjects & $\begin{array}{l}\text { NIDDM patients } \\
\text { with normoalbuminuria }\end{array}$ & $\begin{array}{l}\text { NIDDM patients } \\
\text { with nephropathy }\end{array}$ & $p$-value \\
\hline Previous antihypertensive treatment (\%) & 0 & 30 & 83 & $a, b, c$ \\
\hline $\begin{array}{l}\text { WHO questionnaire history } \\
\text { of myocardial infection (\%) }\end{array}$ & 0 & 9.4 & 7.7 & $d, e$ \\
\hline Stroke $(\%)$ & 4.5 & 3.8 & 9.6 & NS \\
\hline \multicolumn{5}{|l|}{ Present } \\
\hline A ngina pectoris (\%) & 0 & 9.4 & 26.9 & $b, c, d$ \\
\hline ECG signs of ischaemic heart disease & 5 & 20 & 49 & $a, b, c$ \\
\hline Left ventricular hypertrophy & 0 & 9 & 16 & b \\
\hline Intermittent claudication (\% ) & 4.5 & 13.2 & 46.2 & $b, c, f$ \\
\hline $\begin{array}{l}\text { Reduced systolic blood pressure } \\
\text { on big toe }(<67 \% \text { of arm) (\%) }\end{array}$ & 13.6 & 30.1 & 69.2 & $b, c, d$ \\
\hline Smokers (\%) & 50 & 47 & 50 & NS \\
\hline
\end{tabular}

a $p<0.001$ comparing control subjects vs NIDDM patients with normoalbuminuria; ${ }^{b} p<0.001$ comparing control subjects vs NID DM patients with nephropathy; ${ }^{c} p<0.001$ comparing NID D M patients with normoal buminuria vs nephropathy;

$d p<0.01$ comparing control subjects vs N I D D M patients with normoalbuminuria; ${ }^{e} \mathrm{p}<0.01$ comparing control subjects vs NID D M patients with nephropathy; ${ }^{f} p<0.05$ comparing control subjects with NIDDM patients with normoal buminuria

\section{M ethods}

A II patients were studied in our laboratory after having discontinued antihypertensive treatment for 2 weeks (if on treatment). A II subjects were studied after an overnight fast, the diabetic patients omitting their morning insulin or oral antidiabetic agent (if any). The study was carried out between 08.00 and 13.00 hours, and all measurements were performed with the patient in the supine position and in the fasting state.

In all diabetic patients glomerular filtration rate (G FR ) was measured after a single i.v. injection of $3.7 \mathrm{M} \mathrm{Bq}{ }^{51} \mathrm{Cr}$-labelled EDTA at 08.00 hours by determining the radioactivity in venous blood samples taken from the other arm 180, 200, 220, and 240 min after injection [21].

Transcapillary escape rate of albumin (TE $\left.R_{a b b}\right)$ is defined as the fraction of intravascular mass of albumin I M V $V_{\text {alb }}$ that passes to the extravascular space per unit of time. It is determined as the rate constant of the practically monoexponential decrease in plasma radioactivity over the first $60 \mathrm{~min}$ after injection of tracer albumin (initial slope method), as calculated by the least squares method. We have described this procedure and the theoretical basis for the calculation of TER alb in detail previously [22, 23]. B riefly, human serum albumin labelled with ${ }^{125}$ (code MIAK, Institute of A tomic Energy, Kjeller, Norway) was injected intravenously in the morning. The tracer preparation contains less than $1 \%$ of free radioactive iodide and by metabolic studies has been demonstrated to behave like endogenous albumin. A bout $40 \mathrm{kBq}$ of the tracer was injected into one arm vein, and seven venous blood samples of $10 \mathrm{ml}$ each were drawn from the other arm before and $10,20,30,40,50$, and 60 min after the injection. Plasma protein concentration was read refractometrically in duplicate with a total solid-meter (A merican O ptical Corp., Scientific Instrument Division, B uffalo, N.Y., U SA ). The plasma radioactivity was expressed as $\mathrm{cpm} / \mathrm{g}$ total plasma protein to cancel out the effects of small plasma volume change during the 1-h sampling period. TE $R_{\text {alb }}$ measurements were accepted only if the correlation coefficient between the time points for blood collection and the corresponding values of a specific radioactivity exceeded 0.85 . B ecause of this criteria seven patients were excluded from the study as mentioned above. The

mean day-to-day coefficient of variation in TE $\mathrm{R}_{\text {alb }}$ of each patient was $9 \%$.

Blood pressure was measured (three measurements) at the start and end of TER alb measurement with a random zero sphygmomanometer ( $\mathrm{H}$ awksley, L ancing, West Sussex, U K) and expressed as the mean value. A cuff size of $25 \times 12 \mathrm{~cm}$ for lean and $30 \times 15 \mathrm{~cm}$ was used for obese patients. D iastolic BP was recorded at the disappearance of the Korotkoff sounds (phase V).

A 12-lead ECG was recorded. The ECG was coded blindly and independently by two trained observers using the M innesota R ating Scale [24]. I schaemic heart disease was diagnosed if the ECG showed signs of probable myocardial infarction ( $M$ innesota $R$ ating Scale 1.1-2) or possible myocardial ischaemia (M innesota R ating Scale 1.3, 4.1-4, 5.1-3, or 7.1), and left ventricular hypertrophy was diagnosed if the $M$ innesota $R$ ating Scale was 3.1 or 3.3.

The World $\mathrm{H}$ ealth Organization cardiovascular questionnaire [25] was used to assess past and present evidence of myocardial infarction, angina pectoris, stroke and peripheral vascular disease. Present medication and smoking habits were also recorded. Smokers were defined as persons smoking more than one cigarette/cigar/pipe per day. A II others being classified as non-smokers. Digital systolic blood pressure in the lower limb was measured in the big toe using a strain-gauge technique [26-28]. The toe to brachial systolic BP ratio was calculated. A ratio of less than $67 \%$ indicated peripheral arterial disease $[26,27]$. The degree of diabetic retinopathy was scored from fundus photography (Canon CFD -602, K awasaki, Japan) through dilated pupils as none, background retinopathy or proliferative retinopathy.

$L$ aboratory measurements. The serum concentration of VW $F$ was measured by microenzyme-linked immunoadsorbent assay, as described previously [29]. Plasma concentration of prorenin was determined by RIA as described previously [30]. Peripheral blood was drawn between 09.00 and 09.30 hours, after at least 30 min rest in the supine position.

$H$ aemoglobin $A_{1 c}$ was measured by high performance liquid chromatography (Bio Rad DIA MAT, Richmond, Calif., USA ) (normal range 4.3-6.2\%). B lood glucose was measured by means of O ne Touch II (Lifescan, M ilpitas, Calif., U SA ). 
Serum creatinine was measured by a reaction rate kinetic technique eliminating pseudo-creatinines [31]. Plasma albumin concentration was measured by immunoturbidimetry ( 0 rion D iagnostica, E spoo, Finland) [32]. U rinary al bumin concentration was measured using an enzyme-linked immunoadsorbent assay and expressed as median of three $24-h$ collections [33].

\section{Statistical analysis}

A II normally distributed values are given as mean \pm SD and all other values are given as median (range).

In comparisons of the non-normally distributed variables the $\mathrm{K}$ ruskal-Wallis test of variance was used to test for differences between the three groups. If differences were found, the $M$ ann-Whitney test was used for comparisons between two groups. For all other normally distributed variables analysis of variance (A N OVA) was performed in order to test for differences between the three groups. If differences were found, the Student's t-test was used for comparison between two groups. The chi-square test was used for evaluating frequencies. Covariance analysis was performed with systolic and diastolic $B P$ in order to account for differences in blood pressure between the three groups for TE $R_{\text {alb. }}$.

When considering possible association to TE $R_{\text {alb }}, V W F$ and prorenin, multiple regression analysis was used. The following variables were entered into the univariate analysis: sex, age, duration of diabetes, $\mathrm{H} \mathrm{bA}_{10}$, blood glucose, systolic and diastolic BP, smoking, macrovascular disease, retinopathy, prorenin, vWF and TE $R_{a \mid b}$. A II variables significant at a $10 \%$ level were included in the multiple regression analysis, and stepwise forward selection was used. Plasma vW F, prorenin and urinary albumin excretion were logarithmically transformed before inclusion in the analysis. A p-value (two-tailed) less than 0.05 was considered statistically significant. A II calculations were made with a commercially available program, Statgraphic (STSC, R ockville, M d., U SA ).

Results

Tables 1 and 2 show the clinical data of the three groups. The groups were well-matched with regard to sex, age, and B M I. Patients with diabetic nephropathy had a higher prevalence of retinopathy, macroangiopathy, blood pressure elevation, previous antihypertensive treatment, insulin therapy and elevated $\mathrm{HbA}_{1 \mathrm{c}}$ as compared to patients with normoalbuminuria. The prevalence of maculopathy was higher in NIDDM patients with nephropathy; 31 (95\% confidence interval 19-45) vs $9(3-21) \%$ in the normoalbuminuric group $(p<0.01)$. The prevalence of smoking did not differ between the groups. The urinary albumin excretion rate, serum creatinine and BP were comparable in the non-diabetic group and in the normoalbuminuric NID D M group. The latter group had a higher prevalence of previous antihypertensive treatment and macroangiopathy.

Figure 1 illustrates the individual TER alb values. $D$ iabetic patients with and without nephropathy had significantly elevated TE $R_{\text {alb }}$ values $\left(\% \quad I M V_{a l b} / h\right)$ as compared to the non-diabetic control group: 7.9 $(4.3-13.7), \quad 7.4$ (3.7-16.4), and 6.0 (3.4-8.7),

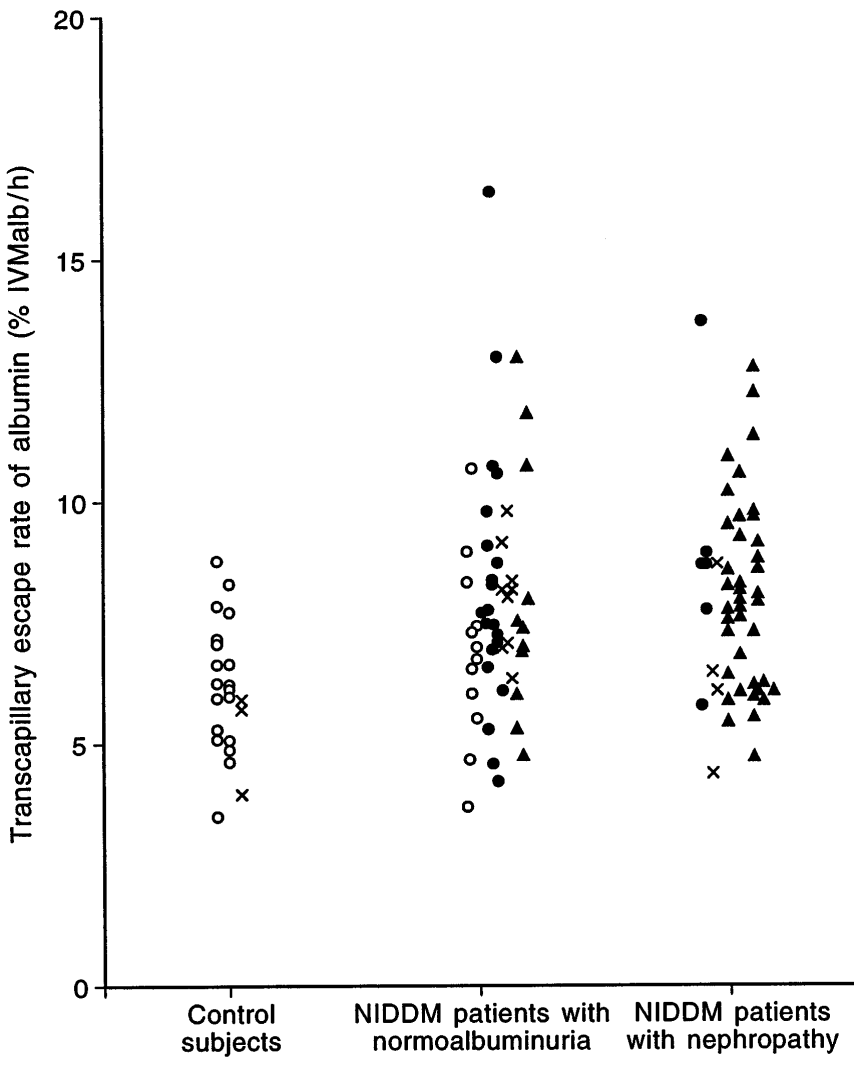

Fig. 1. Transcapillary escape rate of albumin in non-diabetic subjects and NIDD M patients with normoalbuminuria or diabetic nephropathy. Patients without renal or extrarenal vascular complications ( $\bigcirc$ ); patients with diabetic retinopathy and no macroangiopathy (O); patients with macroangiopathy and no retinopathy $(x)$; patients with retinopathy and macroangiopathy $(\boldsymbol{\Delta})$

$(p<0.001)$, respectively. Furthermore, the nephropathic patients tended to have elevated TE $R_{\text {alb }}$ values when compared to normoalbuminuric NIDDM patients without vasculopathy $\left(n=12, T E R_{\text {alb }}\right.$ 6.8[3.710.7], $p=0.09$ ). No significant correlation between $T E R_{\text {alb }}$ and albuminuria or GFR was found in the diabetic groups. U nivariate regression analysis with the previously mentioned continuous and class variables revealed systolic and diastolic BP and smoking to be associated with high TE $\mathrm{R}_{\text {alb }}$ in the normoalbuminuric NIDDM group and an association between retinopathy, $\log _{10}$ prorenin, $\log _{10}$ VWF, and TE $R_{\text {alb }}$ in the nephropathic group. The multiple regression analysis showed that diastolic BP $(p<0.001)$ and smoking $(p<0.05)$ were correlated $\left(r^{2}=0.28\right)$ with TER ${ }_{\text {alb }}$ in NIDDM patients without nephropathy. The same analysis revealed only a significant correlation $\left(r^{2}=0.12\right)$ between $\log _{10}$ prorenin and TE $R_{\text {alb }}$ in NIDDM patients with nephropathy $(p<0.05)$.

Figure 2 shows that the distribution of serum VWF is positively skewed. Diabetic patients with nephropathy had significantly higher values as compared to patients without, and non-diabetic subjects; 


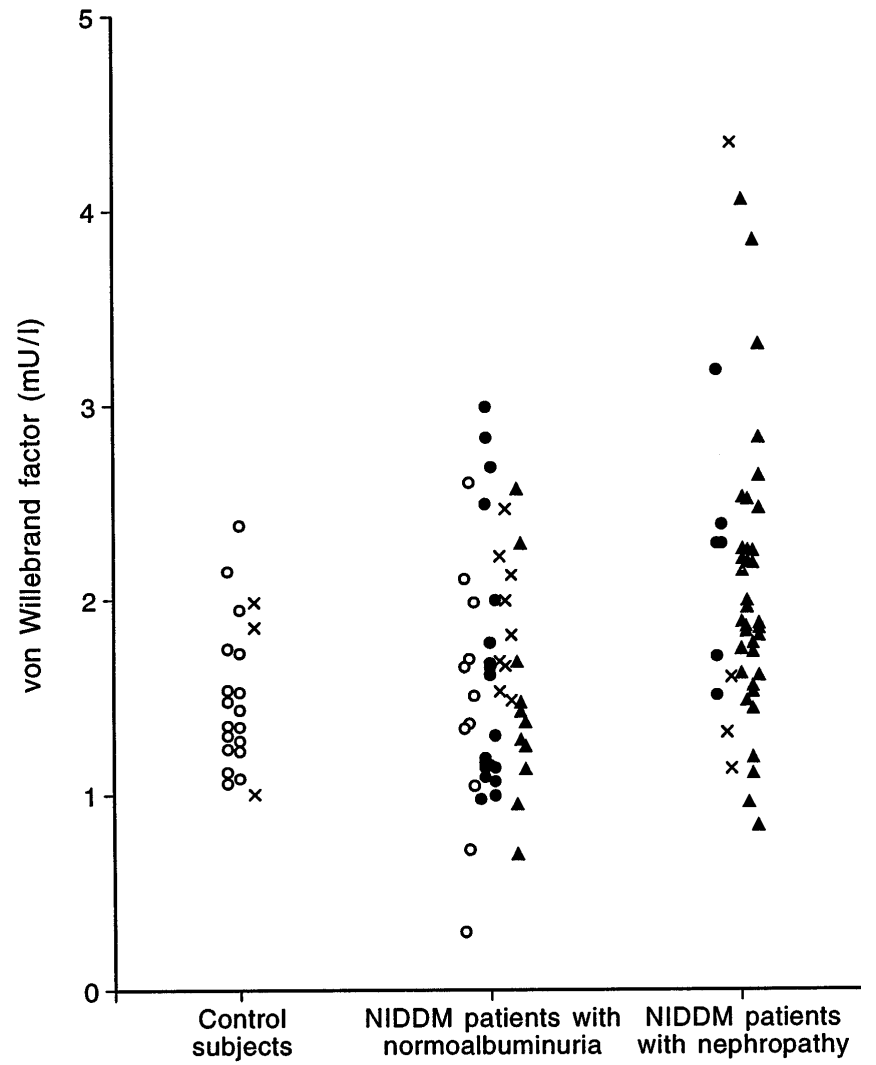

Fig. 2. Von Willebrand factor in non-diabetic subjects and NID D M patients with normoalbuminuria or diabetic nephropathy. Patients without renal or extrarenal vascular complications ( $\bigcirc$ ); patients with diabetic retinopathy and no macroangiopathy (O); patients with macroangiopathy and no retinopathy $(\times)$; patients with retinopathy and macroangiopathy $(\mathbf{\Delta})$

$2.07(0.83-4.34), 1.60(0.30-2.99)$ and $1.50(1.00-2.38)$ $\mathrm{IU} / \mathrm{ml}(\mathrm{p}<0.001)$, respectively. U nivariate regression analysis with exactly the same variables as analysed in relation to TER $\mathrm{R}_{\mathrm{alb}}$, revealed no association between $\mathrm{VWF}$ and any of these variables in the normoalbuminuric group while diastolic blood pressure, blood glucose, smoking, prorenin, albuminuria and $T E R_{\text {alb }}$ were correlated to VWF in the nephropathic group. The multiple regression analysis showed that plasma prorenin $(p<0.001)$, albuminuria $(p<0.01)$ and blood glucose $(p<0.05)$ were correlated $\left(r^{2}=0.32\right)$ with vWF in NIDDM patients with nephropathy. We found no association between the level of $\mathrm{VWF}$ and presence/absence of retinopathy and/or macroangiopathy.

Patients with nephropathy had much higher values of plasma prorenin concentrations as compared to normoalbuminuric, NIDDM patients, and nondiabetic subjects: 272 (56-2405), 192 (18-813), and 85 (28-246) $\mathrm{mlU} / \mathrm{l}, \quad(\mathrm{p}<0.001)$, respectively (Fig.3). The difference between the two latter groups was also significant $(p<0.001)$. The multiple regression analysis revealed a significant correlation $\left(r^{2}=0.08, p<0.01\right)$ between $\mathrm{HbA}_{1 \mathrm{c}}$ and prorenin in

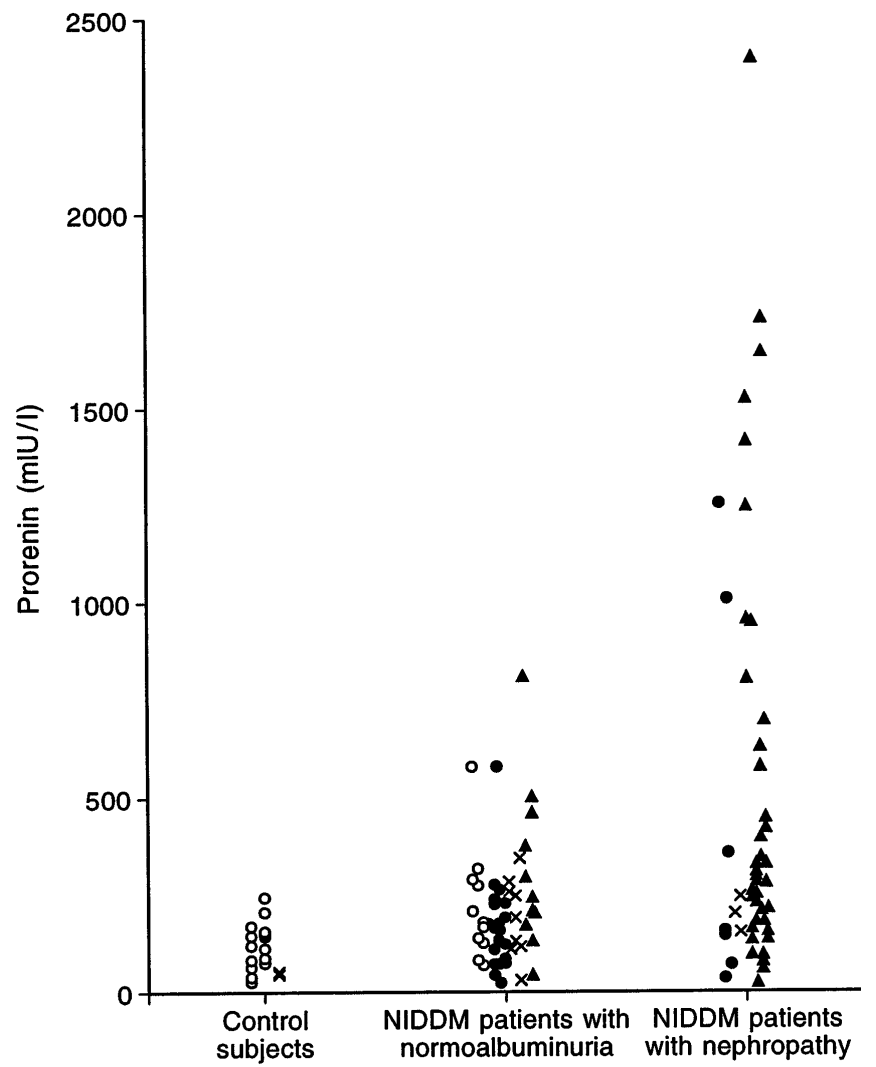

Fig. 3. Prorenin in non-diabetic subjects and NIDDM patients with normoalbuminuria or diabetic nephropathy. Patients without renal or extrarenal complications (O); patients with diabetic retinopathy and no macroangiopathy (O); patients with macroangiopathy and no retinopathy $(x)$; patients with retinopathy and macroangiopathy $(\boldsymbol{\Delta})$

the normoalbuminuric group, and showed that vWF $(p<0.001), R_{\text {alb }}(p<0.01)$ and diabetes duration $(p<0.05)$ were correlated $\left(r^{2}=0.30\right)$ with plasma prorenin concentration in patients with diabetic nephropathy. The distribution of plasma prorenin is positively skewed and dominated by patients with retinopathy and macroangiopathy. The IVM $M_{\text {alb }}$ (mmol), as measured from plasma volume (human serum albumin labelled with ${ }^{125}$ ) and plasma albumin concentrations, was slightly higher in the control subjects compared to NIDDM patients with (N.S.) and without $(p<0.05)$ diabetic nephropathy, $1.67 \pm 0.32,1.59 \pm 0.35$, and $1.55 \pm 0.29$, respectively.

\section{Discussion}

O ur cross-sectional case control study demonstrates that albuminuria reflects generalized vascular damage (retinopathy and macroangiopathy) which is associated with abnormalities in several of the endothelial cell functions. A correlation between markers of different endothelial dysfunction was demonstrated in patients with diabetic nephropathy. 
While this is in accordance with endothelial dysfunction being manifest by measurement of different markers, there was not a uniform relationship of the markers to different types of diabetic tissue damage. The vWF was increased only in NIDDM with nephropathy, whereas abnormal TE R and increased prorenin occurred in NID D M with and without nephropathy. Whereas the vWF was not particularly related to macrovascular disease or retinopathy, the prorenin was mainly raised in those with both macrovascular disease and retinopathy. The cross-sectional nature of our study precludes determination of whether these abnormalities, and presumed endothelial dysfunction, are a consequence of vascular damage or could be associated with the underlying pathology. It should be stressed that strict criteria for diagnosing diabetic nephropathy in our patients were applied [18]. This is crucial since approximately $25 \%$ of albuminuric NIDDM patients are suffering from a nondiabetic glomerulopathy [18]. Previous studies in IDDM patients with abnormally elevated urinary albumin excretion rate with or without diabetic retinopathy have documented raised TER alb [3-6], vWF $[7,8]$, and plasma prorenin $[9,11,12]$.

It has become clear that the vascular endothelium is involved in the regulation of various processes, e. g. haemostasis, fibrinolysis, vasomotor control, vascular smooth muscle cell growth, and vascular permeability, all of which may play a role in the pathogenesis of diabetic micro- and macroangiopathy [34]. It is difficult to measure these endothelial functions but the plasma concentration of VWF, a high molecular glycoprotein synthesized mainly by endothelial cells, may act as a non-specific marker of endothelial dysfunction $[35,36]$. O ur findings are in agreement with most studies demonstrating elevated vWF in microor macroalbuminuric patients with NIDDM $[16,37]$ and IDDM $[7,8,38]$. H owever, the possibility that the raised VWF may be secondary to renal impairment and delayed clearance of vWF cannot be excluded. I n contrast, L amberton et al. [39] found clearly elevated plasma concentration of $V W F$ in a mixed group of IDDM and NIDDM patients but the elevation was not related to presence/absence of retinopathy or proteinuria. A recent prospective study suggests that dysfunction of vascular endothelium as indicated by raised VWF may be a link between albuminuria and atherosclerotic cardiovascular disease in NIDDM [37]. Furthermore, a high concentration of VWF is an index of increased risk for reinfarction and mortality in diabetic and non-diabetic survivors of myocardial infarction [40]. Other markers of generalized vascular endothelial cell damage, e.g. raised plasma thrombomodulin concentration have also been demonstrated in NIDDM patients with microand macroalbuminuria [41].

O riginally, L uetscher et al. [9] demonstrated an association between increased plasma prorenin activity and microvascular complications in IDDM patients. The same association was later demonstrated in a homogeneous group of IDDM patients with microangiopathy [9] in a heterogeneous group of IDDM and NID D M [12] and further established in our NID D M patients with micro- and macroangiopathy. This abnormality is related to the development of microvascular disease in the eye and kidney and is at least in part due to decreased clearance of prorenin from the circulation (endothelial dysfunction), increased production from extrarenal sources or both $[12,42]$. The above mentioned cross-sectional studies suggest that prorenin might serve as a marker of microvascular disease. Furthermore, a prospective study has suggested that increased plasma prorenin activity can predict the development of retinopathy and nephropathy in young ID D M patients [11]. U nfortunately, we lack information on this important issue in NIDDM patients.

The overall leakage of albumin from plasma to the interstitial fluid space was increased both in NIDDM patients with and without nephropathy. The contribution to this increase, from various organs and tissues with highly different permeability surface area product, cannot be evaluated in man. The point that renal albumin loss contributes less than $1 \%$ to the outflux of albumin from plasma to interstitial fluid (approximately $8.7 \mathrm{~g} / \mathrm{h}$ or $209 \mathrm{~g} / 24 \mathrm{~h}$ ) can be mentioned, however. The transendothelial passage of albumin occurs predominantly in the microvasculature. The TE $R_{a l b}$ is determined by the permeability-surface area product and the transcapillary hydrostatic pressure gradient [43]. The microvascular permeability is governed by the size and charge-selective properties of the vessel wall. Changes in the size and charge selectiveproperties of the microvasculature may occur due to structural lesions [23] and/or biochemical abnormalities, e.g. in heparan sulphate proteoglycan [15]. R ecent findings signal that loss of charge selectivity contributes to the elevated TER $R_{a l b}$ in IDDM patients with diabetic nephropathy [44]. The mechanisms involved in the raised TE $R_{\text {alb }}$ seem to differ between our patients with and without nephropathy. Blood pressure and smoking were associated with the high TE $R_{a l b}$ in the normoalbuminuric NIDDM patients. Previous studies have demonstrated that systemic blood pressure elevation accelerates $T E R_{\text {alb }}$ while acute and chronic blood pressure reduction normalize TE $R_{\text {alb }}$ in both diabetic and non-diabetic subjects $[23,45-47]$. R eduction of hydrostatic pressure in the microcirculation has been suggested as a likely factor. D irect [48] and indirect evidence suggest that capillary hydrostatic pressure is elevated in IDDM patients $[47,49]$, while normal capillary pressure (finger nail fold) has been reported in normotensive NIDDM patients [50]. H owever, increased capillary pressure has been documented in essential hypertension [51] and hypertension was prominent in our 
NID D M patients with ( $83 \%$ ) and without ( $30 \%$ ) diabetic nephropathy. The association between smoking and elevated TER $\mathrm{R}_{\mathrm{alb}}$ in our NIDDM patients has also been demonstrated in non-diabetic subjects [52]. Several factors may contribute such as carbon monoxide [53], nicotine [54], and acute intermittent blood pressure elevation in association with smoking [55].

O ur study revealed no association between TE $R_{\text {alb }}$ and actual blood glucose concentration or $\mathrm{HbA}_{1 \mathrm{c}^{\circ}} \mathrm{El}$ evated TER $\mathrm{alb}_{\mathrm{a}}$ has been demonstrated during poor metabolic control in patients with short-term uncomplicated IDDM [56] and NIDDM [57]. Strict metabolic control for a few weeks induced normalization of TER $\mathrm{alb}_{\mathrm{b}}$ in both these groups [56, 57]. Finally, it should be stressed that even 1 year of strict metabolic control in patients with long-standing ID D M with microangiopathy has no beneficial influence on the elevated TER alb [5]. No such data are available in NID DM patients.

$B$ ased on the above-mentioned findings it can be suggested that elevated transendothelial passage of albumin (and other plasma proteins) may cause diabetic microangiopathy according to the concept of plasmatic vasculosis, i.e. increased extravasation of plasma proteins and their deposition into the wall of the microvasculature is the basis of the morphogenesis of diabetic microangiopathy, originally advocated by $L$ endrum [58] and/or be a consequence of diabetic microangiopathy as suggested by Parving [23]. A ortic endothelial permeability to albumin and lipoproteins is highly correlated in animals [59]. Furthermore, repeated endothelial cell injury and increased lipid entry have been suggested as initiating events in atherogenesis [60]. A nimal studies have demonstrated increased aortic endothelial cell death and enhanced transendothelial macromolecular transport in experimental diabetes, hypertension, and during nicotine consumption [54, 61, 62]. D iabetes, hypertension, cigarette smoking are well-known risk factors for macroangiopathy.

A cknowledgements. We acknowledge the assistance of M s. B . J ensen and M s. M . I psen in conducting the study.

\section{References}

1. B orch-J ohnsen K, K reiner S (1987) Proteinuria: value as predictor of cardiovascular mortality in insulin dependent diabetes mellitus. B MJ 294: 1651-1654

2. Parving $\mathrm{H}-\mathrm{H}, \mathrm{H}$ ommel $\mathrm{E}, \mathrm{M}$ athiesen $\mathrm{E}$ R et al. (1988) Prevalence of microalbuminuria, arterial hypertension, retinopathy and neuropathy in patients with insulin-dependent diabetes. B M J 296: 156-160

3. Parving H -H , R asmussen SM (1973) Transcapillary escape rate of albumin and plasma volume in short- and longterm juvenile diabetics. Scand J Clin L ab Invest 32: 81-87

4. Parving H-H, R ossing N (1973) Simultaneous determination of the transcapillary escape rate of albumin and IgG in normal and long-term juvenile diabetic subjects. Scand J Clin Lab Invest 32: 239-244

5. Feldt-R asmussen B (1986) Increased transcapillary escape rate of albumin in type 1 (insulin-dependent) diabetic patients with microalbuminuria. D iabetologia 29: 282-286

6. Nørgaard K, J ensen T, Feldt-R asmussen B (1993) Transcapillary escape rate of albumin in hypertensive patients with type 1 (insulin-dependent) diabetes mellitus. Diabetologia 36: 57-61

7. Porta M , Towsend C, Clover G M et al. (1981) E vidence for functional endothelial cell damage in early diabetic retinopathy. Diabetologia 20: 597-601

8. Jensen T (1989) Increased plasma level of von Willebrand factor insulin-dependent diabetic patients with incipient nephropathy. B MJ 298: 27-28

9. L uetscher JA , K ramer FB, Wilson D M , Schwartz H C, B ryer-A sh M (1985) Increased plasma inactive renin in diabetes mellitus. A marker of microvascular complications. $\mathrm{N}$ Engl J Med 312: 1412-1417

10. Feldt-R asmussen B, M athiesen E R, D eckert T et al. (1987) Central role for sodium in the pathogenesis of blood pressure changes independent of angiotensin, aldosterone and catecholamines in type 1 (insulin-dependent) diabetes mellitus. D iabetologia 30: 610-617

11. Wilson D M, L uetscher JA (1990) Plasma prorenin activity and complications in children with insulin-dependent diabetes mellitus. N E ngl J M ed 323: 1101-1106

12. Franken A A M , D erkx FH M , M an in't Veld A J et al. (1990) $\mathrm{H}$ igh plasma prorenin in diabetes mellitus and its correlation with some complications. J Clin E ndocrinol 71: 10081015

13. Lieberman J, Sastre A (1980) Serum angiotensin-converting enzyme: elevations in diabetes mellitus. A nn Intern M ed 93: 825-826

14. J ensen T, Feldt-R asmussen B, B jerre-K nudsen J, D eckert $T$ (1989) Features of endothelial dysfunction in early diabetic nephropathy. L ancet i:461-463

15. D eckert T, Feldt-R asmussen $B, B$ orch-J ohnsen $K$, Jensen T, Kofoed-E nevoldsen A (1989) A lbuminuria reflects widespread vascular damage. The Steno hypothesis. Diabetologia 32: 219-226

16. Chen J -W, G all M-A, D eckert M, J ensen J S, Parving $\mathrm{H}-\mathrm{H}$ (1995) Increased serum concentration of von Willebrand factor in non-insulin dependent diabetic patients with and without diabetic nephropathy. BMJ 311: 1405-1406

17. N ielsen F S, R ossing P, B ang LE et al. (1995) O $n$ the mechanisms of blunted nocturnal decline in arterial blood pressure in N ID D M patients with diabetic nephropathy. D iabetes 44: 783-789

18. Parving H-H, Gall M-A, Skøtt P et al. (1992) Prevalence and causes of albuminuria in non-insulin-dependent diabetic patients. K idney Int 41: 758-762

19. H other-N ielsen O, Faber O, Sørensen NS, Beck-Nielsen H (1988) Classification of newly diagnosed diabetic patients as insulin-requiring or non-insulin-requiring based on clinical and biochemical variables. D iabetes C are 11: 531-537

20. Faber O, B inder C (1977) C-peptide response to glucagon:a test for the residual $\beta$-cell function in diabetes mellitus. D $\mathrm{i}$ abetes 26: 605-610

21. B röchner-M ortensen J (1972) A simple method for the determination of glomerular filtration rate. Scand J Clin L ab Invest 30: 271-274

22. Parving H-H, G yntelberg F (1973) Transcapillary escape rate of albumin and plasma volume in essential hypertension. Circ R es 32: 643-651

23. Parving H-H (1975) M icrovascular permeability to plasma proteins in hypertension and diabetes mellitus in man - on 
the pathogenesis of hypertensive and diabetic microangiopathy. D an Med Bull 22: 217-233

24. Blackburn H, K eys A, Simonson E, R autaharju P, Punsar S (1960) The electrocardiogram in population studies: a classification system. Circulation 21: 1160-1175

25. R ose G A, B lackburn H, G illum R F, Prineas R J (1982) Cardiovascular survey methods. WHO Monograph Series 56: 162-165

26. Carter SA, L ezack J D (1971) Digital systolic pressures in the lower limb in arterial disease. Circulation 43: 905-914

27. N ielsen PE , B ell G, L assen N A (1972) The measurement of digital systolic blood pressure by strain gauge technique. Scand J Clin L ab Invest 29: 371-379

28. A pelqvist J, Castenfors J, L arsson J, Stenström A, A gardh C-D (1989) Prognostic value of systolic ankle and toe blood pressure levels in outcome of diabetic foot ulcer. D iabetes Care 12: 373-378

29. Ingerslev J (1987) A sensitive ELISA for von Willebrand factor (VWF :A g). Scand J Clin L ab Invest 47: 143-149

30. Sealey J E, G allagher J F, A tlas SA, H esson TE, L aragh J H (1982) Q uantitation of inactive renin in human and dog plasma: techniques for activation. Clin $\mathrm{Exp} H$ ypertens $\mathrm{A}$ 4: 2185-2191

31. Larsen K (1972) Creatinine assay by a reaction - kinetic principle. Clin Chim A cta 41: 209-217

32. Spencer K, Price CP (1979) K inetic immunoturbidimetry: The estimation of albumin. Clin Chim A cta 95: 263-276

33. Feldt-R asmussen B , D inesen B , D eckert M (1985) E nzyme immunoassay: an improved determination of urinary albumin in diabetics with incipient nephropathy. Scand J Clin L ab Invest 45: 539-544

34. H sueh WA, A nderson PW (1992) H ypertension, the endothelial cell, and the vascular complications of diabetes mellitus. H ypertension 20: 253-263

35. B oneu B, A bbal M, Plante J, Bierne R (1975) Factor-V III complex and endothelial damage. $L$ ancet 75(i):1430

36. Stehouwer CDA , D onker A J M (1993) U rinary albumin excretion and cardiovascular disease risk in diabetes mellitus: is endothelial dysfunction the missing link? J N ephrol 6 (2): 72-92

37. Stehouwer CDA, Nauta JJP, Zeldenrust GC, Hackeng W H L , D onker A J M , den Ottolander G J H (1992) U rinary albumin excretion, cardiovascular disease, and endothelial dysfunction in non-insulin-dependent diabetes mellitus. L ancet 340 (ii): 319-323

38. Stehouwer CDA, Stroes ESG, Hackeng WHL, Mulder PGH, den Ottolander GJH (1991) von Willebrand factor and development of diabetic nephropathy in ID D M. Diabetes 40: 971-976

39. L amberton R P, Goodman A D, Kassoff A et al. (1984) von Willebrand factor (VIII R:A g), fibronectin, and insulinlike growth factors I and II in diabetic retinopathy and nephropathy. Diabetes 33: 125-129

40. Jansson J -H, Nilsson TK, Johnson O (1991) von Willebrand factor in plasma: a novel risk factor for recurrent myocardial infarction and death. B r H eart J 66: 351-355

41. I washima Y, Sato T, Watanabe K et al. (1990) Elevation of plasma thrombomodulin level in diabetic patients with early diabetic nephropathy. D iabetes 39: 983-988

42. Kem DC, Brown RD (1990) R enin - from beginning to end. N Engl J Med 323: 1136-1137

43. Lassen NA, Parving $\mathrm{H}-\mathrm{H}$, R ossing N (1974) Filtration as the main mechanism of overall transcapillary protein escape from the plasma. M icrovasc R es 7: 1-4

44. B ent- $H$ ansen $L$, Feldt-R asmussen $B, K$ verneland A, D eckert T (1993) Plasma disappearance of glycated and non-glycated albumin in type 1 (insulin-dependent) diabetes mellitus: evidence for charge dependent alterations of the plasma to lymph pathway. D iabetologia 36: 361-363

45. Parving H-H (1991) I mpact of blood pressure and antihypertensive treatment on incipient and overt nephropathy, retinopathy, and endothelial permeability in diabetes mellitus. Diabetes Care 14: 260-269

46. Parving H-H, Smidt U M (1986) H ypotensive therapy reduces microvascular albumin leakage in insulin-dependent diabetic patients with nephropathy. Diabet Med 3: 312315

47. Parving H-H, K astrup J, Smidt U M (1985) R educed transcapillary escape rate of albumin during acute blood pressure-lowering in type 1 (insulin-dependent) diabetic patients with nephropathy. D iabetologia 28: 797-801

48. Sandeman DD, Shore A C, Tooke JE (1992) R elation of skin capillary pressure in patients with insulin-dependent diabetes mellitus to complications and metabolic control. N Engl J M ed 327: 760-764

49. Parving $\mathrm{H}-\mathrm{H}$, V iberti $\mathrm{G} \mathrm{C}$, K een $\mathrm{H}$, Christiansen J S, L assen NA (1983) H emodynamic factors in the genesis of diabetic microangiopathy. M etabolism 32: 943-949

50. Shore A C, Jaap A J, Tooke JE (1994) Capillary pressure in patients with NID D M. D iabetes 43: 1198-1202

51. Williams SA , B oolell M, M acG regor G A , Smaje L H, Wasserman SM, Tooke JE (1990) Capillary hypertension and abnormal pressure dynamics in patients with essential hypertension. Clin Sci 79: 5-8

52. Jensen $E$ W, A ndersen $H B, N$ ielsen SL, Christensen NJ (1992) L ong-term smoking increases transcapillary escape rate of albumin. Scand J Clin L ab Invest 52: 653-656

53. Parving $\mathrm{H}-\mathrm{H}$ (1972) The effect of hypoxia and carbon monoxide exposure on plasma volume and capillary permeability to albumin. Scand J Clin L ab Invest 30: 49-56

54. L in S-J, H ong C-Y, C hang M -S, Chiang B N, Chien S (1992) Long-term nicotine exposure increases aortic endothelial cell death and enhances transendothelial macromolecular transport in rats. A rterioscler Thromb 12: 1305-1312

55. Groppelli A , G iorgi D M A , O mboni S, Parati G, M ancia G (1992) Persistent blood pressure increase induced by heavy smoking. J H ypertens 10: 495-499

56. Parving $\mathrm{H}-\mathrm{H}$, N oer I, D eckert T et al. (1976) The effect of metabolic regulation on microvascular permeability to small and large molecules in short-term juvenile diabetics. Diabetologia 12: 161-166

57. O'H are JA, Ferriss J B, Twomey B, O'Sullivan DJ (1983) Poor metabolic control, hypertension, and microangiopathy independently increase the transcapillary escape rate of al bumin in diabetes. D iabetologia 25: 260-263

58. L endrum A C (1963) The hypertensive diabetic kidney as a model of so-called collagen diseases. Canad M ed A ss J 88: 442-452

59. Stender S, H jelms E (1987) In vivo transfer of cholesterol from plasma into hyman aortic tissue. Scand J Clin Lab Invest 47 [Suppl] 186: 21-29

60. R oss R (1986) The pathogenesis of atherosclerosis - an update. N Engl J Med 314: 488-500

61. L in S-J, H ong C-Y, C hang M-S, Chiang B N , Chien S (1993) Increased aortic endothelial cell death and enhanced transendothelial macromolecular transport in streptozotocin-diabetic rats. D iabetologia 36: 926-930

62. Wu CH, Chi J C, Jerng J S et al. (1990) Transendothelial macromolecular transport in the aorta of spontaneously hypertensive rats. $\mathrm{H}$ ypertension 16: 154-161 